\title{
EVALUASI PENERAPAN UJIAN AKHIR SEKOLAH DASAR BERBASIS STANDAR NASIONAL
}

\author{
Djemari Mardapi \\ Pascasarjana UNY \\ djemarimardapi@yahoo.co.id
}

\begin{abstract}
Abstrak
Tujuan penelitian adalah mengevaluasi penerapan ujian akhir sekolah berbasis standar nasional (UASBN) untuk sekolah dasar. Sampel adalah lima dari 33 propinsi yang dipilih secara purposive, kemudian 20 sekolah dipilih dari kelima propinsi tersebut. Responden adalah Kepala Dinas Pendidikan Nasional Propinsi terpilih, 20 kepala sekolah dasar, 60 orang guru, 800 orang siswa, dan 800 orang tua siswa. Data kuantitative dikumpulkan mengunakan angket dan dianalisis secara deskriptive statistik. Data kualitatif dikumpulkan melalui wawancara dan dianalisis dengan kategori. Hasil penelitian adalah sebagai berikut: (1) Semua kantor dinas pendidikan propinsi dan kabupaten/kota dan sekolah telah mempersiapkan secara baik pelaksanaan UASBN, (2) penulisan butir soal, pencetakan soal, dan distribusi soal dilakukan sesuai dengan prosedur operasinal standar, (3) supervisi pelaksanaan UASBN dilakukan oleh guru dari sekolah lain, (4) kriteria skor kelulusan pada tiga propinsi ditetapkan oleh sekolah, sedangkan di Propinsi Bengkulu dan Nusa tenggara Timus (NT'T) ditetapkan oleh kantor dinas pendidikan kabupaten/kota, (5) semua guru dan hampir semua siswa dan orang tua siswa mengharapkan bahwa UASBN dilakukan secara menerus, dan (6) problem yang dihadapi sekolah adalah kurangnya kemampuan guru pelajaran Matematik dan IPA.
\end{abstract}

Kata kunci: evaluasi, UASBN, ujian akhir 
EVALUATION OF THE IMPLEMENTATION OF THE FINAL EXAMINATION FOR PRIMARY SCHOOLS BASED ON NATIONAL STANDARD

\author{
Djemari Mardapi \\ Pascasarjana UNY \\ djemarimardapi@yahoo.co.id
}

\begin{abstract}
The purpose of this study was to evaluate the implementation of the final examination for primary schools based on national standards (UASBN). The sample were five provinces purposively selected from 33 provinces. Twenty schools/madrasahs were selected from five provinces. The respondents were five heads of provincial and 10 heads of the district education offices, 20 principals of primary schools, 60 teachers, 800 pupils, and 800 parents. The quantitive data were collected with questionnaires and analyzed with descriptive statistics. The qualitative data were collected through interview and analyzed using categories. The findings are: (1) all provinces and district education offices and schools have a good preparation in conducting the UASBN, (2) the item writings, test print, and test distribution are conducted according to the standard operation procedures, (3) the supervision of the UASBN is conducted by teachers from other schools, (4) the passing score criterion is determined by schools in three provinces, but it is determined by district/city education offices in Bengkulu and Nusa Tenggara Timur (NTT), (5) all teachers, almost all pupils, and parents expect that UASBN should be conducted continuosly, and (6) the problem that the schools have is the ability of the teachers in teaching mathematics, and science subjects.
\end{abstract}

Key words: evaluation, UASBN, final examination 


\section{Pendahuluan}

Persaingan kualitas sumber daya manusia (SDM) pada era global pada dasarnya merupakan persaingan kualitas pendidikan. Sumber daya manusia adalah produk dari pendidikan dan/atau pelatihan. Oleh karena itu semua negara berusaha untuk meningkatkan kualitas pendidikan. Pemerintah Indonesia juga terus berusaha meningkatkan kualitas pendidikan, mulai dari pendidikan dasar sampai pendidikan tinggi.

Terkait dengan hal di atas, sebenarnya ada beberapa kebijakan yang dapat dilakukan oleh pemerintah untuk meningkatkan kualitas SDM, salah satu di antaranya adalah meningkatkan kualitas pendidikan. Bahkan, kualitas pendidikan merupakan kunci utama dalam upaya peningkatan SDM. Semakin tinggi kualitas pendidikan di suatu negara, semakin tinggi pula kualitas SDM negara tersebut. Kualitas SDM yangn tinggi akan meningkatkan kesejahteraan masyarakat.

Memetik pengalaman dari negara maju dalam menghadapi perdagangan bebas nanti generasi muda Indonesia harus memiliki karakteristik kualitas sebagai berikut: (1) karakteristik kualitas dasar, yaitu beriman dan bertaqwa kepada Tuhan Yang Maha Esa, berbudi pekerti luhur, cerdas, berdisiplin, sehat jasmani dan rohani, berkepribadian yang mantap dan mandiri, dan memiliki tanggung jawab kemasyarakatan dan kebangsaan, (2) karakteristik kualitas instrumental, kualitas yang harus selalu diperbarui sesuai dengan perubahan, yang meliputi kemampuan produktif, kemampuan sumber daya, kemampuan berkomunikasi, kemampuan memecahkan masalah, dan kemampuan menggunakan ilmu pengetahuan dan teknologi.

Pemerintah Indonesia berusaha keras agar Sumber Daya Manusia (SDM) yang dimiliki berkualitas tinggi. Sebenarnya sudah lama tekad pemerintah meningkatkan kualitas bangsa. Hal ini ditegaskan melalui Kepmen Ristek No. 02/M/Kp/II/2000 tentang Kebijakan Strategis Pembangunan Ilmu Pengetahuana dan Teknologi (IPTEK) Nasional yang menyebutkan bahwa prioritas utama dan pertama adalah pembinaan sumbar daya manusia (SDM). 
Salah satu usaha yang dilakukan pemerintah adalah penetapan standar nasional pendidikan. Di dalamnya terdapat pasal perlunya ujian nasional yang bertujuan untuk memantau pencapaian kompetensi lulusan. Beberapa negara maju seperti Kanada, Hungaria, Prancis, Belanda, dan Inggris tetap menggunakan ujian akhir secara nasional untuk menentukan keberhasilan belajar siswa. Ujian akhir yang dilakukan sendiri oleh masingmasing sekolah atau masing-masing daerah bisa membuat daerah puas dengan hasil yang dicapai, walau belum mampu berkompetisi secara global. Oleh karena itu perlu dilaksanakan ujian nasional yang hasilnya dapat digunakan untuk meningkatkan kualitas pendidikan.

Ujian nasional pada dasarnya adalah evaluasi terhadap pencapaian program pendidikan. Evaluasi adalah kegiatan untuk mengetahui pencapaian suatu program. Evaluasi memberi informasi untuk kebijakan dalam dua cara. Pertama evaluasi memberi informasi bagi pembuat kebijakan tentang keadaan pendidikan atau pencapaian belajar suatu grup tertentu. Kedua, informasi evaluasi digunakan sebagai piranti administratif untuk menerapkan kebijakan. Evaluasi terhadap pelaksanaan Ujian Akhir Sekolah Berstandar Nasional (UASBN) dilakukan mulai dari persiapan sampai pada pelaksanaan.

Evaluasi memerlukan data kuantitatif dan kualitatif. Data ini diperoleh melalui pengukuran. Menurut Ebel (1972) pengukuran adalah pemberian angka pada seseorang atau sesuatu objek yang dimaksudkan untuk membedakan tingkat orang atau objek itu mengenai hal (trait) yang diukur dengan cara sistimatis. Sementara itu, Campbell (Guilford 1954) menyatakan: measurement as the assignment of numerals to objects or events according to rules. Senada dengan ahli lainnya, Kerlinger (1986) menyatakan bahwa pengukuran adalah pemberian angka pada objek-objek atau kejadiankejadian menurut sesuatu aturan. Nunnally (1978) juga menjelaskan bahwa pengukuran itu terdiri dari aturan-aturan untuk memberikan angka/bilangan kepada objek dengan cara yang sedemikian rupa sehingga dapat mempresentasikan secara kuantitatif sifat-sifat objek tersebut.

Pengukuran dapat dilakukan melalui tes dan dapat pula tidak melalui tes. Tes itu sendiri menurut Anastasi (1976) dan Brown (1976), merupakan suatu pengukuran yang objektif dan standar terhadap sampel perilaku. 
Sejalan dengan ahli lainnya, Cronbach (1970) mengatakan bahwa tes adalah prosedur yang sistematis untuk mengobservasi perilaku seseorang dan mendeskripsikan perilaku itu dengan skala numerik atau sistem kategori.

Selanjutnya, hasil pengukuran ini digunakan untuk melakukan penilaian dan/atau evaluasi. Terkait dengan penilaian dan evaluasi, ada beberapa ahli yang mengatakan bahwa ada kesamaan pengertian antara evaluasi dan penilaian, namun para ahli lainnya menganggap bahwa kedua hal itu berbeda. Nitko (1996) menjelaskan bahwa penilaian adalah proses memperoleh informasi untuk tujuan pengambilan keputusan tentang kebijakan pendidikan, kurikulum, program pendidikan, dan kegiatan belajar siswa. Sependapat dengan Nitko, Linn dan Gronlund (1995) menjelaskan bahwa penilaian merupakan suatu proses sistematik untuk menentukan seberapa jauh tujuan instruksional telah dicapai siswa.

Di sisi lain, Nitko (1996) menjelaskan evaluasi adalah proses memperoleh informasi untuk menimbang kebaikan kinerja siswa. Informasi ini digunakan untuk mengetahui apakah tujuan yang telah ditentukan itu tercapai atau tidak. Sementara itu evaluasi berasal dari kata kerja "to evaluate" yang salah satu artinya adalah melihat/menimbang apakah suatu program yang telah selesai dikerjakan menghasilkan seperti yang telah ditetapkan sebagai tujuan program tersebut.

Worthen dan Sanders (Worthen \& Sanders, 1973: 129) menjelaskan bahwa evaluasi adalah penentuan nilai dari sesuatu, yang mencakup pengumpulan informasi yang akan digunakan dalam penentuan nilai dari program, hasil, prosedur, atau tujuan; atau kegunaan/manfaat potensial dari pendekatan yang dirancang untuk mencapai tujuan yang sudah ditentukan. Selanjutnya dinyatakan bahwa evaluasi merupakan proses penggambaran, pencarian, dan pemberian informasi yang sangat bermanfaat bagi pengambil keputusan dalam menentukan alternatif keputusan.

Berdasarkan pengertian di atas, dalam kegiatan evaluasi terkandung makna adanya pengumpulan informasi, penggambaran, pencarian, dan penyajian informasi guna pengambilan keputusan tentang program yang dilaksanakan. Adapun tujuan evaluasi, sebagaimana dinyatakan oleh Valadez dan Bamberger (1994: 13) adalah untuk menilai kesesuaian rencana 
program dengan metode pelaksanaannya untuk mencapai tujuan, menilai hasil program, baik hasil yang diharapkan maupun yang tidak diharapkan, dan menilai faktor-faktor yang mempengaruhi keberhasilan program.

Pelaksanaan pendidikan di Indonesia yang selama ini dilakukan belum memenuhi harapan. Hal ini ditunjukkan oleh hasil survei dari TIMMS-R bahwa kemampuan siswa SLTP di bidang Matematika dan Ilmu Alam tergolong rendah, yaitu pada urutan ke 33 dari 39 peserta (TIMMS-R, 2001). Kemampuan siswa SLTP dalam bidang Matematika dan Ilmu Alam telah bergeser dari Amerika dan Eropa ke Asia tetapi tidak termasuk Indonesia. Hal ini menunjukkan bahwa apa yang dilakukan untuk meningkatkan kualitas pendidikan selama ini belum memberikan hasil yang berarti, atau kalah bersaing dengan negara tetangga seperti Malaysia dan Singapura.

Laporan dari Depdikbud (1998) menyatakan bahwa dengan mengggunakan hasil Ebtanas yang berupa NEM, selama lima tahun terakhir kualitas pendidikan kita tidak mengalami banyak perubahan, walau tantangan dari masyarakat cukup besar. Hasil studi yang dilakukan oleh TIMMS-R (Third International Mathematics and Sciences Study-Repeated, 1998) menunjukkan bahwa kemampuan siswa Sekolah Lanjutan Pertama (SLTP) kita dibanding dengan negara lain tergolong rendah yaitu pada urutan 33 dari 39 negara untuk bidang studi matematika, sedang untuk bidang studi sains pada urutan ke 35. Kemampuan siswa SLTP kita berada di bawah Malaysia, apalagi dibanding dengan Singapore, Indonesia jauh tetinggal.

Penelitian yang dilakukan Djemari Mardapi, dkk (1999) menunjukkan bahwa Nilai Ebtanas Murni yang dicapai peserta didik SLTP dan SMA adalah dalam interval 4,00 sampai 6,00, kecuali mata pelajaran PPKN dan Bahasa Indonesia. Inipun karena persyaratan lulus untuk kedua mata pelajaran tersebut adalah minimum 6,0. Hal ini menunjukkan bahwa usaha peningkatan kualitas pendidikan yang telah dilakukan belum memberi hasil seperti yang diharapkan.

Otonomi dalam bidang pendidikan diikuti dengan kewajiban bagi daerah untuk meningkatkan kualitas pendidikan. Usaha peningkatan kualitas mencakup tugas melaksanakan ujian akhir pada setiap jenjang pendidikan. Hasil ujian ini berfungsi untuk memantau pencapaian standar 
kompetensi lulusan suatu satuan pendidikan. Dalam mewujudkan wajib belajar yang bermutu diperlukan ukuran keberhasilannya. Menurut Peraturan Pemerintah (PP) Nomor 19 tentang standar nasional pendidikan, untuk mengetahui pencapaian kompetensi lulusan suatu satuan pendidikan diperlukan ujian nasional. Ujian nasional untuk sekolah dasar dan madrasah ibtidaiyah (SD/MI) menghadapi masalah tentang variasi kemampuan guru dan fasilitas pembelajaran di sekolah/madrasah. Untuk itu tingkat materi dan tingkat kesulitan ujian nasional untuk sekolah dasar harus memperhatikan kondisi sekolah/madarash. Hal ini dapat diatasi melalui penggunakan teknik penyamaaan skor, sehingga tingkat kesulitan soal bisa berbeda, namun hasilnya bisa dibandingkan.

Penilaian hasil belajar oleh pemerintah bertujuan untuk menilai pencapaian kompetesi lulusan secara nasional pada mata pelajaran tertentu dalam kelompok mata pelajaran ilmu pengetahuan teknologi dan dilakukan dalam bentuk ujian nasional (Peraturan Pemerintah No 19, tentang Standar Nasional Pendidikan, pasal 66). Pada jenjang SD/MI/SDLB, atau bentuk lain yang sederajat, Ujian Nasional mencakup mata pelajaran Bahasa Indonesia, Matematika, dan Ilmu Pengetahuan Alam (Peraturan Pemerintah No 19, tentang Standar Nasional Pendidikan, pasal 70). Selanjutnya pada pasal 67, dijelaskan bahwa untuk melaksanakan tugasnya, yakni penilaian hasil belajar, Pemerintah menugaskan Badan Standar Nasional Pendidikan (BSNP) untuk menyelenggarakan ujian nasional. Untuk melaksanakan pasal-pasal di atas Mendiknas menetapkan Peraturan Menteri Pendidikan Nasional tentang Ujian Akhir Sekolah Berstandar Nasioanl (UASBN) untuk Sekolah Dasar/Madrasah Ibtidaiyah/Sekolah Dasar Luar Biasa (SD/MI/SDLB) tahun pelajaran 2007/2008 (Permen Diknas RI No. 39 Tahun 2007 tentang Ujian Akhir Sekolah Berstandar Nasioanl). Teknis pelaksanaan UASBN mengacu kepada prosedur operasioanl standar (POS) UASBN yang ditetapkan oleh BSNP (Permen Diknas No. 39 Th. 2007 pasal 1 ayat 8).

Sesuai dengan POS, UASBN diselenggarakan oleh Penyelenggara UASBN Tingkat Pusat, Penyelenggara UASBN Tingkat Provinsi, Penyelenggara UASBN Tingkat Kabupaten/Kota, dan Penyelenggara UASBN Tingkat Sekolah/Madrasah. Unsur-unsur, tugas dan tanggung 
jawab dari setiap penyelenggara terdapat pada POS UASBN (2007: 2-5). Pada POS tersebut dijelaskan tentang tugas dan tanggung jawab masingmasing penyelenggara UASBN.

Permendiknas Nomor 39 Tahun 2007 tentang Ujian akhir sekolah berstandar nasional (UASBN) untuk sekolah dasar/madrasah ibtidaiyah/sekolah dasar luar biasa (SD/MI/SDLB) Tahun pelajaran 2007/2008. Permendiknas No. 39 Tahun 2007 di atas, selain menjelaskan kegunaan hasil ujian nasional juga menggambarkan bahwa mulai tahun 2008 Pemerintah akan menyelenggarakan UASBN. Oleh karena tahun 2008 ini merupakan tahun pertama bagi pemerintah untuk menyelenggarakan UASBN, maka perlu adanya evaluasi yang dimaksudkan untuk mengungkap pelaksanaan UASBN yang meliputi persiapan dan pelaksanaan UASBN di daerah.

Berdasarkan latar belakang dan kajian pustaka, pertanyaan pada evaluasi ini adalah sebagai berikut.

1. Bagaimana persiapan penyelenggara UASBN tingkat Provinsi, Kabupaten/Kota, dan Sekolah dalam melaksanakan UASBN?

2. Bagaimana penyiapan soal UASBN, yang meliputi penyusunan, penggandaan, dan pendistribusiannya?

3. Bagaimana sistem pengawasan pelaksanaan, penentuan kelulusan dan kendala-kendala yang dihadapi dalam UASBN?

4. Apa harapan dan saran stakeholders untuk perbaikan penyelenggaraan UASBN?

\section{Metode Penelitian}

Penelitian ini dilakukan di program Pascasarjana Universitas Negeri Yogyakarta. Populasi penelitian ini adalah 33 provinsi yang melaksanakan UASBN. Evaluasi pelaksanaan UASBN dilakukan terhadap 5 (lima) provinsi sebagai sampel dari 33 provinsi yang ada di Indonesia yang dipilih secara purposif. Pemilihan lima provinsi ini berdasarkan hasil ujian nasional yang mencakup kategori menengah dan rendah, yaitu Jawa Tengah, Bengkulu, Kalimantan Selatan, Sulawesi Tengah, dan Nusa Tenggara Timur (NTT). Tiap provinsi dipilih tiga Sekolah Dasar (SD) 
masing-masing satu sekolah kategori baik, cukup, dan kurang serta satu Madrasah Ibtidaiyah (MI) kategori menengah. Jadi secara nasional semua ada 20 sekolah yang terdiri atas 15 SD dan 5 MI yang dijadikan sampel pemantauan. Pengambilan data lapangan dilakukan selama 4 hari, salah satunya adalah hari terakhir UASBN, yaitu pada tanggal 15 Mei 2008.

Jenis data yang dianalisis meliputi profil sekolah, fasilitas belajar, dukungan internal dan eksternal, persiapan dan pelaksanaan UASBN. Sumber data penelitian ini adalah: (1) Penyelenggara UASBN Provinsi, yaitu Kasi Kur Dinas Provinsi), (2) Penyelenggara UASBN Kabupaten/Kota, yaitu Kasi Kur Dinas Kabupaten/Kota, (3) Penyelenggara UASBN di sekolah, yaitu Kepala Sekolah SD/MI, (4) Guru, (5) Siswa, dan, (6) Orang tua. Data yang dikumpulkan dalam evaluasi ini berasal dari siswa, guru, kepala sekolah, pejabat dinas pendidikan kabupaten/kota, dan pejabat dinas pendidikan provinsi.

Secara keseluruhan, sebaran responden UASBN yang meliputi kepada dinas, kepala sekolah, guru, siswa, dan orang tua dapat dilihat pada Tabel-1. Data yang diperlukan diperoleh melalui kuesioner kepala sekolah, kuesioner guru, kuesioner siswa, kuesioner dan wawancara dengan kepala sekolah serta observasi, kuesioner dan wawancara dengan dinas pendidikan kabupaten/kota, kuesioner dan wawancara dengan dinas pendidikan provinsi. Instrumen yang digunakan adalah: profil sekolah, fasilitas belajar, dukungan internal dan eksternal, dan persiapan dan pelaksanaan UASBN.

Teknik analisis data yang digunakan adalah statistik deskriptif kuantitatif dan kualitatif. Deskriptif kuantitatif digunakan untuk mendeskripsikan persentase dan rerata. Deskriptif kualitatif digunakan untuk menjelaskan data kualitatif, yang meliputi tentang pendapat responden terkait dengan persiapan, pelaksanaan, kendala yang dihadapi, dan saran-saran perbaikan responden tentang UASBN. 
Tabel 1. Sebaran Responden UASBN Secara Nasional

\begin{tabular}{|l|l|c|c|c|c|c|}
\hline \multirow{2}{*}{ No. } & \multirow{2}{*}{ Responden } & \multicolumn{5}{|c|}{ Banyaknya Sampel } \\
\cline { 3 - 7 } & & Sekolah & Kota & Kab & Provinsi & Nasional \\
\hline 1. & Kapala Dinas Prop & - & - & - & 1 & $5 \times 1=5$ \\
\hline 2. & Kepala Dinas Kab/Kota & - & 1 & 1 & - & $5 \times 2=10$ \\
\hline 3. & Ka Sek SD/MI & 1 & 1 & 3 & 4 & $5 \times 4=20$ \\
\hline 4. & Guru & 3 & 3 & 9 & 12 & $5 \times 12=60$ \\
\hline 5. & Siswa & 40 & 40 & 120 & 160 & $5 \times 160=800$ \\
\hline 6. & Orang tua & 40 & 40 & 120 & 160 & $5 \times 160=800$ \\
\hline
\end{tabular}

\section{Hasil Penelitian dan Pembahasan}

Hasil pemantauan tentang kepemilikan dokumen-dokumen UASBN seperti Keputusan Menteri (Kepmen), Prosedur Operasional Standar (POS), Standar Kompetensi Lulusan (SKL), dan kisi-kisi soal oleh pihak penyelenggara UASBN, disajikan pada Tabel-2.

Tampak pada Tabel-2 bahwa, 100\% penyelenggara tingkat provinsi telah memiliki semua dokumen UASBN. Demikian juga, 100\% penyelenggara tingkat provinsi telah memiliki semua dokumen UASBN. Demikian juga, $100 \%$ penyelenggara tingkat kabupaten/kota telah memiliki dokumen UASBN seperti Permen, POS, dan SKL. Untuk dokumen kisi-kisi soal, masih terdapat 10\% penyelenggara tingkat kabupaten/kota yaitu kota Semarang yang belum memiliki. Selanjutnya, 100\% penyelenggara tingkat sekolah telah memiliki dokumen UASBN seperti Permen, SKL, dan kisikisi soal. Untuk dokumen POS, ada sebanyak $11.77 \%$ penyelenggara tingkat sekolah yaitu SD N 48 Solok Babatan yang belum memiliki.

Tabel 2. Kepemilikan Dokumen UASBN

\begin{tabular}{|l|c|c|c|c|}
\hline \multirow{2}{*}{$\begin{array}{c}\text { Penyelenggara } \\
\text { UASBN }\end{array}$} & \multicolumn{4}{|c|}{ Persentase (\%) Kepemilikan Dokumen UASBN } \\
\cline { 2 - 5 } & Permen & POS & SKL & Kisi-kisi Soal \\
\hline Provinsi & 100 & 100 & 100 & 100 \\
\hline Kabupaten/Kota & 100 & 100 & 100 & 90 \\
\hline Sekolah & 100 & 88.33 & 100 & 100 \\
\hline
\end{tabular}


Sosialisasi penyelenggaraan UASBN Tahun 2008 dilakukan oleh tim dari pusat, provinsi, kabupaten/kota, pokja/rayon/kecamatan, dan sekolah. Tim tersebut melakukan sosialisasi pada wilayah kerja masingmasing. Tim provinsi melakukan sosialisasi pada penyelenggara UASBN tingkat kabupaten/kota. Tim kabupaten/kota melakukan sosialisasi pada penyelenggara UASBN tingkat pokja/rayon/kecamatan. Tim dari pokja/rayon/kecamatan melakukan sosialisasi pada sekolah-sekolah. Sekolah sebagai unit terdepan dalam pelaksanaan UASBN telah melakukan sosialisasi kepada guru, siswa, dan orang tua siswa.

Bentuk sosialisasi yang dilakukan oleh pihak sekolah meliputi pertemuan formal dengan guru dan orang tua siswa. Untuk siswa, pihak sekolah memberikan penjelasan secara langsung dalam kelas. Jawaban guru, siswa dan orang tua siswa terhadap pertanyaan apakah pernah menerima sosialisasi (penjelasan) dari pihak sekolah tentang pelaksanaan UASBN disajikan pada Tabel 3. Tampak pada Tabel 3 bahwa, 100\% guru, siswa, dan orang tua bahwa mereka pernah menerima sosialisasi dari pihak sekolah tentang pelaksanaan UASBN. Penyelenggaraan UASBN melakukan persiapan di semua jajaran yang terkait mulai dari dinas pendidikan provinsi, dinas pendidikan kabupaten/kota, sekolah, siswa, dan orang tua siswa.

Tabel 3. Tanggapan Guru, Siswa, dan Orang Tua tentang Sosialisasi UASBN yang Dilakukan Sekolah

\begin{tabular}{|l|c|}
\hline $\begin{array}{c}\text { Sasaran sosialisasi } \\
\text { dari Sekolah }\end{array}$ & $\begin{array}{c}\text { Persentase (\%) menerima } \\
\text { sosialisasi UASBN dari sekolah }\end{array}$ \\
\hline Guru & 100 \\
\hline Siswa & 100 \\
\hline Orangtua & 100 \\
\hline
\end{tabular}

Persiapan yang dilakukan oleh Dinas Pendidikan Kabupaten/Kota dalam menghadapi UASBN disajikakan pada Tabel 4. Semua penyelenggara UASBN tingkat Kabupaten/Kota mengeluarkan SK penetapan sekolah penyelenggara UASBN. Semua penyelenggara UASBN tingkat kabupaten/kota mendistribusi kisi-kisi ke sekolah penyelenggara 
UASBN lebih 3 bulan sebelumnya. Semua Penyelenggara UASBN tingkat kabupaten/kota melakukan sosialisasi ke sekolah penyelenggara.

Tabel 4. Persiapan Dinas Pendidikan Kabupaten/Kota Menghadapi UASBN

\begin{tabular}{|c|l|c|c|}
\hline \multirow{2}{*}{ No. } & \multirow{2}{*}{ Kegiatan yang dilakukan } & Persentase Jawaban \\
\cline { 3 - 4 } 1. & $\begin{array}{l}\text { Bupati/Walikota menetapkan penyelenggara UASBN } \\
\text { tingkat Kabupaten/Kota bersama Dinas Pendidikan } \\
\text { Kab/Kota, Depag, dan Dewan Pendidikan }\end{array}$ & 90 & 10 \\
\hline 2. & $\begin{array}{l}\text { Penyelenggara UASBN tingkat Kabupaten/Kota } \\
\text { mengeluarkan SK penetapan sekolah penyelenggara } \\
\text { UASBN }\end{array}$ & 100 & 0 \\
\hline 3. & $\begin{array}{l}\text { Penyelenggara UASBN tingkat Kabupaten/Kota } \\
\text { mendistribusi kisi-kisi ke sekolah penyelenggara } \\
\text { UASBN lebih 3 bulan sebelumnya }\end{array}$ & 100 & 0 \\
\hline 4. & $\begin{array}{l}\text { Penyelenggara UASBN tingkat Kabupaten/Kota } \\
\text { melakukan sosialisasi ke sekolah penyelenggara }\end{array}$ & 100 & 0 \\
\hline
\end{tabular}

Persiapan yang dilakukan oleh sekolah dalam menghadapi UASBN tampak dalam Tabel 5. Tabel tersebut memperlihatkan bahwa semua sekolah memberi pelajaran tambahan pada mata pelajaran matematika, Bahasa Indonesia, dan IPA. Semua sekolah memberi tambahan kesejahteraan guru yang melaksanakan pelajaran tambahan. Semua sekolah melaksanakan pertemuan dengan guru dan orang tua siswa untuk mempersiapkan para siswanya.

Tabel 5. Persiapan Sekolah Menghadapi UASBN

\begin{tabular}{|c|l|c|c|}
\hline \multirow{2}{*}{ No. } & \multicolumn{1}{|c|}{ Kegiatan yang dilakukan } & \multicolumn{2}{c|}{ Persentase Jawaban } \\
\cline { 3 - 4 } & \multicolumn{1}{|c|}{$\begin{array}{c}\text { Ya } \\
\text { Bahasa Indonesia, dan IPA }\end{array}$} & 100 & 0 \\
\hline 2. & $\begin{array}{l}\text { Menambah kesejahteraan guru yang melaksanakan } \\
\text { pelajaran tambahan }\end{array}$ & 100 & 0 \\
\hline 3. & Melaksanakan pertemuan dengan guru & 100 & 0 \\
\hline 4. & Melaksanakan pertemuan dengan orang tua siswa & 100 & 0 \\
\hline
\end{tabular}


Persiapan yang dilakukan oleh orang tua siswa dalam menghadapi UASBN dapat dilihat di Tabel 6. Tabel tersebut menunjukkan bahwa hampir semua $(91,89 \%)$ orang tua memberi dorongan belajar kepada anaknya. Hampir separuh $(44,14 \%)$ orang tua mengikutsertakan anaknya ke bimbingan belajar di lembaga luar sekolah. Hampir semua (96,4\%) orang tua siswa memberi dukungan fasilitas belajar untuk anaknya.

Berdasarkan hasil wawancara dari dinas pendidikan provinsi, dinas pendidikan kabupaten/kota dan kepala sekolah diperoleh informasi sebagai berikut: (1) Kabupaten/kota memilih guru-guru sekolah dasar yang berkualitas untuk diusulkan menjadi calon penyusun soal UASBN tingkat provinsi, (2) Guru-guru yang terpilih tersebut dilatih dalam penyusunan soal UASBN oleh Puspendik selama tujuh hari, (3) Soal yang telah tersusun direview oleh tim dengan melibatkan dosen dari Lembaga Pendidikan Tenaga Kependidikan, (4) Soal yang telah direview dan diperbaiki menjadi master soal UASBN dan disimpan oleh dinas pendidikan provinsi.

Tabel 6. Persiapan Orang Tua Siswa Menghadapi UASBN

\begin{tabular}{|c|l|c|c|}
\hline \multirow{2}{*}{ No. } & \multicolumn{2}{|c|}{ Kegiatan yang dilakukan } & \multicolumn{2}{|c|}{ Persentase Jawaban } \\
\cline { 3 - 4 } & & Ya & Tidak \\
\hline 1. & Memberi dorongan belajar ke anaknya & 91,89 & 9,01 \\
\hline 2. & $\begin{array}{l}\text { Mengikut sertakan bimbingan belajar } \\
\text { anaknya di lembaga di luar sekolah }\end{array}$ & 44,14 & 55,86 \\
\hline 3. & Memberi dukungan fasilitas belajar & 96,40 & 3,60 \\
\hline
\end{tabular}

Pendistribusian soal UASBN dilakukan secara bertahap. Soal yang diberikan kepada masing-masing sekolah hanya soal yang diujikan pada hari tersebut. Adapun proses pendistribusian soal UASBN dilakukan dalam dua cara sebagai berikut.

Cara pertama dilakukan oleh Provinsi Jawa Tengah dan Nusa Tenggara Timur, yaitu dengan langkah: (1) Soal UASBN hasil penggandaan disimpan di dinas pendidikan dengan pengawalan ketat dari pihak kepolisian dan pejabat setempat, (2) Pembentukan posko-posko penyimpanan soal UASBN yang dijaga oleh polisi dan wakil pejabat dinas pendidikan. Posko-posko berfungsi untuk pendistribusian soal ke tingkat 
kecamatan, (3) Setiap hari wakil sekolah penyelenggara UASBN mengambil soal yang diujikan pada hari tersebut ke posko kecamatan.

Cara kedua dilakukan oleh Provinsi Bengkulu, Sulawesi Tengah dan Kalimantan Selatan, dengan langkah: (1) Soal UASBN hasil penggandaan disimpan di kapolda/kapolsek dan dijaga oleh wakil dari dinas pendidikan beserta wakil dari kepolisian setempat, (2) Setiap hari wakil dari sekolah penyelenggara UASBN mengambil soal yang diujikan pada hari tersebut.

Informasi yang didapat dari Kasikur Provinsi menunjukkan bahwa, penentuan kelulusan sudah sesuai dengan Permendiknas no. 39/2007 tentang UASBN untuk SD/MI/SDLB tahun pelajaran 2007/2008, yakni diserahkan kepada sekolah, yakni guru mapel UASBN atau kepala sekolah masing-masing. Hal ini berarti sesuai dengan POS UASBN.

Terkait dengan batas kelulusan UASBN, para guru yang terlibat mengajar di kelas-VI menyatakan batas kelulusan UASBN pada umumnya untuk matematika dianggap cukup. Untuk Bahasa Indonesia dan IPA dianggap masih tinggi. Di samping itu, masih ada sebanyak 34.85\% terutama guru-guru dari Provinsi NT'T dan Kalsel yang menganggap bahwa batas kelulusan UASBN baik Matematika, Bahasa Indonesia, maupun IPA masih terlalu tinggi.

Terkait dengan tingkat kesulitan soal mapel UASBN, para guru menyatakan bahwa tingkat kesulitan mata pelajaran UASBN baik matematika, bahasa Indonesia maupun IPA, berada pada kategori sedang sampai sulit. Hanya sedikit guru yang menganggap bahwa tingkat kesulitan mapel UASBN dirasa sangat sulit kecuali guru-guru dari Provinsi NTT.

Mengenai batas kelulusan dan perkiraan lulus UASBN, hampir 60\% siswa menyatakan batas kelulusan UASBN dianggap cukup, namun 40\%nya masih menganggap tinggi. Peluang untuk lulus UASBN nampak optimis, lebih dari 77\% menyatakan peluang lulusnya tinggi, sedangkan keinginan untuk melanjutkan studi ke SMP/MTs, nampak hampir 100\%. Untuk lebih jelasnya, hal ini dapat dilihat pada Tabel 7. 
Tabel 7. Pendapat Siswa tentang Batas Kelulusan UASBN, Peluang Lulus dan Keinginan untuk Melanjutkan ke SMP/MTs

\begin{tabular}{|c|l|r|r|c|}
\hline \multirow{2}{*}{ No } & \multicolumn{2}{|c|}{ Pertanyaan/Pernyataan } & \multicolumn{3}{|c|}{ Persentase Jawaban * } \\
\cline { 3 - 5 } & & 1 & \multicolumn{1}{c|}{2} & \multicolumn{1}{c|}{3} \\
\hline 1 & Batas kelulusan UASBN yang ditetapkan saat ini & 0,00 & 59,46 & 40,54 \\
\hline 2 & Perkiraan anda lulus UASBN & 0,90 & 21,62 & 77,48 \\
\hline 3 & Keinginan anda melanjutkan ke SMP/MTs & 0,00 & 1,82 & 98,18 \\
\hline
\end{tabular}

Keterangan: *

$1=\mathrm{kurang} / \mathrm{rendah}, 2=$ sedang, $3=\mathrm{baik} /$ tinggi

Terkait dengan tingkat kesulitan soal mapel UASBN, para siswa pada umumnya menyatakan bahwa tingkat kesulitan mata pelajaran UASBN baik bahasa Indonesia, matematika, maupun IPA, berada pada kategori sedang, namun ada $25.16 \%$ siswa yang menganggap bahwa mapel matematika sulit terutama dari Provinsi NT'T. Untuk lebih jelasnya dapat dilihat pada Tabel 8.

Tabel 8. Pendapat Siswa tentang Tingkat Kesulitan Mapel UASBN

\begin{tabular}{|l|r|r|r|}
\hline \multirow{2}{*}{ Mata Pelajaran } & \multicolumn{3}{|c|}{ Persentase Jawaban * } \\
\cline { 2 - 4 } & 1 & 2 & 3 \\
\hline Bahasa Indonesia & 27,02 & 68,41 & 4,56 \\
\hline Matematika & 14,69 & 60,14 & 25,16 \\
\hline IPA & 13,91 & 73,49 & 12,60 \\
\hline
\end{tabular}

Keterangan: *

$1=$ mudah, 2 = sedang, $3=$ sulit

Selanjutnya, menurut kepala sekolah dan guru kendala-kendala yang dihadapi dalam melaksanakan UASBN adalah: (1) Tenggang waktu antara sosialisasi dan pelaksanaan UASBN terlalu pendek, yaitu pada provinsi Jawa Tengah., (2) Lembar Jawaban (LJ) dari percetakan terlambat datang ke penyelenggara provinsi (NTT), (3) Tidak tersedia soal cadangan, (4) Masih adanya peserta yang kurang mengerti cara mengisi LJ, (5) Sekolah belum siap dalam proses pengisian data, (6) Terbatasnya alat, sarana, SDM, dan anggaran. 
Tabel 9. Pandangan Siswa tentang Kendala yang Dihadapi dalam UASBN

\begin{tabular}{|c|c|c|c|c|c|c|c|c|c|c|c|c|c|}
\hline \multirow{2}{*}{ No } & \multirow{2}{*}{ Aspek } & \multicolumn{2}{|c|}{ NTT } & \multicolumn{2}{|c|}{ Sulteng } & \multicolumn{2}{|c|}{ Bengkulu } & \multicolumn{2}{|c|}{ Kalsel } & \multicolumn{2}{|c|}{ Jateng } & \multicolumn{2}{|c|}{ Nasional } \\
\hline & & $\mathrm{f}$ & $\%$ & $\mathrm{f}$ & $\%$ & $\mathrm{f}$ & $\%$ & $\mathrm{f}$ & $\%$ & $f$ & $\%$ & $\mathrm{f}$ & $\%$ \\
\hline 1 & $\begin{array}{l}\text { Kurang belajar } \\
\text { dan disiplin }\end{array}$ & 39 & 31,45 & 52 & 51,49 & 48 & 50,53 & 26 & 38,24 & 79 & 79,80 & 244 & 50,10 \\
\hline 2 & $\begin{array}{l}\text { Sejumlah soal } \\
\text { dirasa sulit }\end{array}$ & 12 & 9,68 & 0 & 0,00 & 32 & 33,68 & 22 & 32,35 & 9 & 9,09 & 75 & 15,40 \\
\hline 3 & $\begin{array}{l}\text { Rasa percaya diri } \\
\text { kurang }\end{array}$ & 7 & 5,65 & 10 & 9,90 & 5 & 5,26 & 1 & 1,47 & 0 & 0,00 & 23 & 4,72 \\
\hline 4 & $\begin{array}{l}\text { Sejumlah matei } \\
\text { belum diajarkan }\end{array}$ & 0 & 0,00 & 0 & 0,00 & 0 & 0,00 & 16 & 23,53 & 1 & 1,01 & 17 & 3,49 \\
\hline 5 & $\begin{array}{l}\text { Lingkungan yang } \\
\text { kurang } \\
\text { mendukung }\end{array}$ & 0 & 0,00 & 14 & 13,86 & 3 & 3,16 & 0 & 0,00 & 0 & 0,00 & 17 & 3,49 \\
\hline 6 & $\begin{array}{l}\text { Waktu ujian } \\
\text { terlalu singkat }\end{array}$ & 7 & 5,65 & 0 & 0,00 & 0 & 0,00 & 0 & 0,00 & 2 & 2,02 & 9 & 1,85 \\
\hline 7 & $\begin{array}{l}\text { Jumlah soal terlalu } \\
\text { banyak }\end{array}$ & 7 & 5,65 & 0 & 0,00 & 0 & 0,00 & 0 & 0,00 & 0 & 0,00 & 7 & 1,44 \\
\hline
\end{tabular}

Menurut siswa terdapat sejumlah kendala yang dihadapi dalam mengikuti UASBN seperti tampak pada Tabel 9. Kendala utama menurut siswa dalam menghadapi UASBN adalah kurangnya belajar. Kurang belajar kemungkinan karena selama ini ujian akhir dilakukan sekolah masingmasing, sehingga kurang memotivasi siswa, karena kecenderungannya semua lulus.

\section{Simpulan}

Hasil evaluasi pelaksanaan UASBN tahun pelajaran 2007/2008 dapat disimpulkan sebagai berikut.

1. Semua provinsi penyelenggara UASBN sudah memiliki semua dokumen UASBN, namun masih terdapat 10\% yang belum memiliki dokumen kisi-kisi soal UASBN. Semua penyelenggara tingkat sekolah telah memiliki dokumen Permendiknas, dan Kisi-kisi soal UASBN, namun masih ada $16.67 \%$ sekolah yaitu yang belum memiliki dokumen POS UASBN. 
2. Sosialisasi penyelenggaraan UASBN 2008 telah dilakukan oleh semua penyelenggara UASBN, secara bertingkat mulai dari pusat, provinsi, kabupaten/kota, dan sekolah.

3. Semua sekolah/madrasah memberi tambahan pelajaran Matematika, Bahasa Indonesia, dan IPA, serta memberi tambahan kesejahteraan bagi guru yang melaksanakan pelajaran tambahan.

4. Hampir semua orang tua siswa $(92 \%)$ memberi dorongan belajar dan dukungan fasilitas belajar ke anaknya dalam menghadapi UASBN.

5. Penyusunan dan penggandaan soal UASBN telah sesuai dengan POS UASBN.

6. Pendistribusian soal UASBN melalui dua cara dan keduanya tidak menyimpang dari POS UASBN.

7. Sistem pengawasan dilakukan lintas sekolah, sesuai dengan POS UASBN.

8. Hampir pada semua daerah, penentuan batas kelulusan ditentukan oleh sekolah, namun di Bengkulu dan NTT dilakukan oleh dinas kabupaten/kota secara bersama-sama di satu provinsi dengan mempertimbangkan kondisi sekolah.

9. Menurut sebagian besar guru dan siswa batas kelulusan dianggap cukup.

10. Harapan para stakeholders untuk tahun-tahun mendatang, UASBN tetap dilanjutkan karena banyak positifnya, namun ada beberpa perbaikan.

11. Saran guru untuk perbaikan penyelenggaran UASBN yang akan datang adalah, penentu kelulusan tetap dilakukan sekolah/madrasah, SKL perlu disederhanakan dan diberi contoh-contoh aplikasinya, kerja sama dengan orang tua dalam membimbing siswa, melengkapi sarana dan prasarana sekolah, memberikan pelatihan dan mengoptimalkan kegiatan Kelompok Kerja Guru ditingkat gugus. 
Jurnal Penelitian dan Evaluasi Pendidikan

\section{Saran}

Saran yang diajukan berdasarkan hasil evalusi adalah sebagai berikut.

1. Perlu pembinaan terhadap kemampuan mengajar dan penguasaan materi ajar bagi guru yang mengajar kelas-VI.

2. Penyebaran POS dan kisi-kisi agar dilakukan seawal mungkin.

3. Faktor guru, sekolah, orang tua, dan eksternal perlu diperhatikan agar dapat berkontribusi positif terhadap pelaksanaan maupun kelulusan dalam UASBN.

4. Pelatihan penulisan soal agar lebih diintensifkan dengan melibatkan guru yang lebih banyak.

5. Pelatihan penggunaan mesin scanner lebih diintensifkan agar petugas scanning di setiap kabupaten/kota benar-benar siap.

6. Pelatihan pembelajaran bagi guru untuk mata pelajaran Bahasa Indonesia, Matematika, dan IPA lebih diintesifkan agar prestasi belajar siswa meningkat.

\section{Daftar Pustaka}

Anastasi, A. (1976). Psycological Testing. New York: MacMillan Publishing Co.

Brown, F. G. (1976). Principles of Educational and Psychological Testing. New York: Holt, Rinehart, and Winston.

Cronbach, L. J. (1970). Essentials of Psychological Testing. New York: Harper \& Row.

Depdikbud. (1998). Keputusan bersama Dirjen Dikdasmen Depdikbud dan Dirjen Binaga Islam Depag, No.423/C/Kep/PP/1998. No. E/344.A/1998 tentang: Pedoman penyelenggaraan EBTANAS tabun pelajaran 1998/1999. Jakarta: Ditjen Dikdasmen.

Mardapi, D. (1999). Estimasi kesalahan pengukuran dalam bidang pendidikan dan implikasinya pada ujian nasional. Pidato pengukuhan guru besar, diucapkan di depan rapat senat terbuka UNY.

244 - Jurnal Penelitian dan Evaluasi Pendidikan Tahun 13, Nomor 2, 2009 
Ebel, R. L (1972). Essentials of educational measurement. (3rd. ed.) Englewood Cliffts, NJ: Prentice Hall Inc.

Guilford, J. P. (1954). Psychometric Methods. (2 $2^{\text {nd }}$ ed). New York: McGrawHill.

Kerlinger, F. N. (1979). Behavioral research: Conceptual approach. New York: Holt Rinehart and Winston.

. (1986). Foundation of Behavior Research. (3 $3^{\text {rd }}$ ed.). New York: Holt, Rinehart, and Winston.

Liu, R. L. \& Grondlund, N. E. (1995). Measurement and Assessment in Teaching. New Jersey: Prentice Hall, Inc.

Nitko, A. J. (1996). Penilaian berkelanjutan berdasarkan kurikulum (PB2K): Kerangka, konsep, prosedur, dan kebijakan. Jakarta: Pusat Pengembangan Agibisnis.

Permendiknas RI No. 39 Tahun 2007 tentang: Ujian Akbir Sekolah Berstandar Nasional untuk SD/MI/SDLB Tabun Pelajaran 2007.

Prosedur Operasi Standar (POS) Ujian Akhir Sekolah Berstandar Nasional Untuk SD/MI/SDLB Tahun Pelajaran 2007/2008.

Valadez, J. \& Bamberger, M. (1994). Monitoring and Evaluationg Social Programs in Developing Countries: A Handbook for Policymakers, Managers, and Researchers. Washington DC: World Bank, Economic Development Institute.

Worthen, B. K. \& Sanders, J. R. (1973). Educational Evaluation: Theory and Practice. Ohio: Charles A. Jones Publishing Co. 